\title{
Three-dimensional variations in the lower limb caused by the Windlass mechanism
}

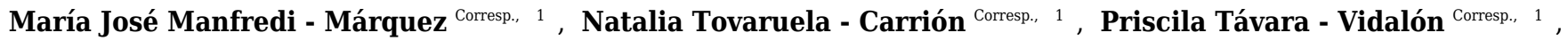

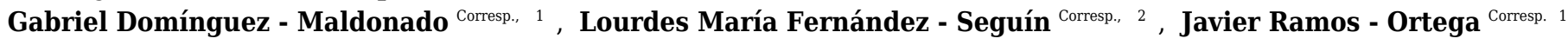 \\ 1 Department of Podiatry, Universidad de Sevilla, Seville, Spain \\ 2 Department of Physiotherapy, Universidad de Sevilla, Seville, Spain \\ Corresponding Authors: María José Manfredi - Márquez, Natalia Tovaruela - Carrión, Priscila Távara - Vidalón, Gabriel Domínguez - Maldonado, Lourdes \\ María Fernández - Seguín, Javier Ramos - Ortega \\ Email address: marmanmar1@alum.us.es, ntovaruela@us.es, santavvid@alum.us.es, gdominguez@us.es, Ifdz@us.es, jrortega@us.es
}

Background. The Windlass mechanism was described as the effect caused by the extension of the first metatarsalphalangeal joint (1st MTPJ). Quantify the degrees of movement produced in the leg by means of the Bioval ${ }^{\circledR}$ sensor system, after performing two measurements in the 1st MTPJ, 45o extension and maximum extension.

Methods. Tests-post-test study with just one intervention group, performed in the Clinical Podiatry Area of the Faculty of Nursing, Physiotherapy and Podiatry of the University of Seville. Subjects were included as of age 20 , with a value from 0 을 to 3 o valgus, Helbing line, a value from 0 to +50 for the Foot Postural Index, and a localisation axis for the normalised subtalar joint. Subjects with surgical operations of the first ray, fractures and surgical operations in the leg, pathologies in the first ray and rheumatic diseases, were excluded. Measurement was performed with the Bioval ${ }^{\circledR}$ system by means of inserting four sensors in the bone structures involved in the Windlass Mechanism.

Results. With the $45^{\circ}$ wedge we observed a direct correlation among the variables extension-plantar flexion 1st MTPJ and rotation of the femur. With maximal extension of the 1st MTPJ we obtained a direct relationship between the variable extension of the 1st MTPJ and the variables plantarflexion and pronosupination of the 1st metatarsal, as well as, with the variables tibia rotation and femur rotation.

Conclusions. Kinematic analysis suggested that, the higher the degree of extension the more movement will be generated. This reduces the level of impact the more distal the structure with respect to the 1st MTPJ, which has an impact on the entire leg. Because of the kinematic system used wasn't suitable, its impact wasn't exactly quantified. 
1 Three-dimensional variations in the lower limb caused by the Windlass mechanism.

\section{Authors:}

3 1. María José Manfredi-Márquez. DP. Clinic Assistant. Department of Podiatry, University of Seville. Centro Docente de Fisioterapia y Podología, C/Avicena, s/n 41009- Seville, Spain. mariajo_manfredi@hotmail.com; marmanmar1@alum.us.es

2. Natalia Tovaruela-Carrión. $\mathrm{DP}$ - PhD. Titular Professor. Department of Podiatry, University of Seville. Centro Docente de Fisioterapia y Podología, C/Avicena, s/n 41009- Seville, Spain.ntovaruela@us.es

3. Priscila Távara-Vidalón. DP. Clinic Assistant. Department of Podiatry, University of Seville. Centro Docente de Fisioterapia y Podología, C/Avicena, s/n 41009- Seville, Spain. priscilatavara16@hotmail.com ; santavvid@alum.us.es

4. Gabriel Domínguez-Maldonado. DP - PhD. Titular Professor. Department of Podiatry, University of Seville. Centro Docente de Fisioterapia y Podología, C/Avicena, s/n 41009- Seville, Spain. gdominguez@us.es

5. Lourdes María Fernández-Seguín. DP - PhD. Titular Professor. Department of Physiotherapy, University of Seville. Centro Docente de Fisioterapia y Podología, C/Avicena, s/n 41009- Seville, Spain.1fdez@us.es

6. Javier Ramos-Ortega. DP - PhD. Titular Professor. Department of Podiatry, University of Seville. Centro Docente de Fisioterapia y Podología, C/Avicena, s/n 41009- Seville, Spain.jrortega@us.es

Corresponding Author's:

María José Manfredi-Márquez. mariajo_manfredi@hotmail.com 
24 Blackground. The Windlass mechanism was described as the effect caused by the extension of

25 the first metatarsalphalangeal joint (1st MTPJ). Quantify the degrees of movement produced in

26 the lower limb by means of the Bioval ${ }^{\circledR}$ sensor system, after performing two measurements in

27 the 1 st MTPJ, $45^{\circ}$ extension and maximum extension.

28 Methods. Tests-post-test study with just one intervention group, performed in the Clinical

29 Podiatry Area of the Faculty of Nursing, Physiotherapy and Podiatry of the University of Seville.

30 Subjects were included as of age 20 , with a value from $0^{\circ}$ to $3^{\circ}$ valgus, Helbing line, a value from

310 to $+5^{\circ}$ for the Foot Postural Index, and a localisation axis for the normalised subtalar joint.

32 Subjects with surgical operations of the first ray, fractures and surgical operations in the leg,

33 pathologies in the first ray and rheumatic diseases, were excluded. Measurement was performed

34 with the Bioval ${ }^{\circledR}$ system by means of inserting four sensors in the bone structures involved in the

35 Windlass Mechanism.

36 Results. With the $45^{\circ}$ wedge we observed a direct correlation among the variables extension-

37 plantar flexion 1st MTPJ and rotation of the femur. With maximal extension of the 1st MTPJ we

38 obtained a direct relationship between the variable extension of the 1st MTPJ and the variables

39 plantarflexion and inversion/eversion of the 1st metatarsal, as well as, with the variables tibia

40 rotation and femur rotation.

41 Conclusions. Kinematic analysis suggested that, the higher the degree of extension the more

42 movement will be generated. This reduces the level of impact the more distal the structure with

43 respect to the 1st MTPJ, which has an impact on the entire leg. Because of the kinematic system

44 used wasn't suitable, its impact wasn't exactly quantified. 
INTRODUCTION

In 1954 Hicks $^{1}$ reported the mechanism by which metatarsalphalangeal extension raise the

47 medial longitudinal arch (MLA) by tensing the plantar fascia (PF) during propulsion, without the assistance of muscular action. This effect is called "Windlass Mechanism" (WM). In his study, it was observed that during passive extension of the hallux, the PF wraps rounds the head of the first metatarsal, increasing its tension and increasing the height of the MLA, thereby reducing the distance between its origin and insertion. Moreover, the increased arch will cause supination of the hindfoot and external rotation of the lower limb. Finally, Hicks revealed the important relationship set out between the PF and first metatarsalphalangeal joint (1st MTPJ). These are the most important players in the implementation of this mechanism, where the subtalar joint (STJ), midtarsal joint (MTJ) and the ankle joint $(\mathrm{AJ})$, in addition to the tibia and femur ${ }^{1-7}$ are also involved.

The first metatarso-digital segment is essential for correct function of the WM, because this is activated with passive extension of the 1 st MTPJ $^{1}$.

Extension of the 1st MTPJ and subsequent plantar flexion of the first ray will lead to MLA elevation by means of increased tension of the PF. Its length reduces and there is modification of the position of all the joints that take part in this mechanism, generating a supination movement in the STJ capable of producing a change in position in the Cyma line, where the talonavicular joint move from a location anterior to the calcaneocuboid joint to a posterior position $^{8,9}$.

At the same time a dorsiflexion movement of the talus occurs inside the AJ which helps to stabilise the foot during gait and external rotation of the lower extremity ${ }^{9}$. Finally, the last 
68 abduction of the forefoot, keeping it anchored to the ground ${ }^{8,9}$. The movements produced in the

$69 \mathrm{WM}$ are triplanar, not only in the sagittal plane ${ }^{8}$.

70 In short, when the arch is raised, the first metatarsal plantar flexes, STJ and the oblique

71 axis of the MTJ supinate, tibia and femur externally rotate and the pelvis moves backwards.

72 Therefore, the foot movement is translated into an ascending chain in the tibia, femur and pelvis ${ }^{1,6}$

73 giving the foot as a whole the necessary stability during the ultimate support phase $\mathrm{e}^{1,5,8-12}$.

74 The WM produce a rotation of the lower limb, but it isn't known to what extent this

75 relationship occurs. It is necessary to know how many degrees of tibial rotation occur when the

76 1st MTPJ is extended, so that this rotation can be applied in the control of pronation during mold

77 making of the phenolic foam in weightbearing.

78 The aims of this study are to quantify the degrees of movement produced in the lower

79 limb by means of the Bioval ${ }^{\circledR}$ sensor system, after performing two measurements in the 1 st

80 MTPJ, $45^{\circ}$ extension and maximum extension.

\section{MATERIAL AND METHODS}

82 Subjects

Tests-post-test study with just one intervention group, performed in the Clinical Podiatry

84 Area of the Faculty of Nursing, Physiotherapy and Podiatry at the University of Seville (Spain)

85 between November 2015 and April 2016. Subjects were selected using convenience sampling; in

86 this case it was subjects belonging to the Faculty of Nursing, Physiotherapy and Podiatry at the

87 University of Seville, considering as inclusion criteria aged over 20. This age threshold was

88 selected because of understanding that up to 17-19 years, in some cases up to 20 years, bone

89 growth physis has not yet closed, which enables more capacity for torsional changes in these

90 segments ${ }^{13}$; a value of $0^{\circ}$ to $3^{\circ}$ valgus in the Helbing line ${ }^{14}$, a value of 0 to +5 for the Foot Posture 
91 Index $(\mathrm{FPI})^{15},{ }^{16}$ and a normalised STJ localisation axis ${ }^{17}$. Exclusion criteria were subjects with

92 surgical operations of the first ray, fractures and surgical operations in the leg, pathologies in the 93 first ray (Hallux Limitus, Hallux Rigidus, Hallux Valgus), rheumatic diseases, refusal to sign the

94 informed consent form. All those who offered to take part in the study gave their informed 95 consent in writing before being recruited. The ethical and legal principles required in any 96 biomedical research essentially considered in the Oviedo Agreement and the Declaration of

97 Helsinki were compliant at all times; in addition there was guarantee of data confidentiality 98 complying with Spanish Law 4/2002, of 14 November, basic regulator of patient autonomy ${ }^{18,19}$.

\section{Methodology}

A data collation form was designed; the first step was to record the sex and age of subjects. Some shorts then provided to facilitate performing measurements set out in our 102 protocol.

Subjects subsequently removed their shoes and their weight and height were measured 104 with Mechanical Column Scale with Tallimeter (Seca 711. Class III). The Helbing`s line ${ }^{14}$ and the 105 FPI $^{15,16}$ were measurement with the subject standing on a podoscope.

Extension of the 1st MTPJ was measured with the subject in supine position to verify the movement of this ${ }^{9}$. Subsequently, the STJ axis location was done using the palpation technique 108 reported by $\mathrm{Kirby}^{17}$. This technique was made by one research with 10 years of experience. After 109 scanning the footprint with the Plantar Digital Scanner CbsScanFoot model EDP-G2-A with the 110 location axis of STJ marked, the degrees of this axis were quantified ${ }^{17}$, using longitudinal 111 bisection of the foot. For this, the software Autocad $\AA^{20-22}$ (Autodesk Inc, San Rafael, California) 112 was used. 
114 is a system of biomechanical analysis (or analysis of human movement), that allows to value, 115 visualize and quantify the movement in the three planes of the space; sagittal plane (flexion / 116 extension), frontal (adduction / abduction) and transverse (internal / external rotation) of all joints 117 in static and dynamic with a frequency of $30 \mathrm{~Hz}$. the information via Bluetooth, and represent it in the form of graphs.

121 value a joint by reference to the sensor that precedes it, requiring at least two sensors ${ }^{24}$. The studied variables were: extension - flexion 1st MPTJ (yellow sensor), inversion/eversion 1st MTT (red sensor), tibia rotation (blue sensor) and femur rotation (green sensor). Independent sensors record isolated movement. The studied variables were: Extension 1st MPTJ (yellow sensor), plantarflexion 1st MTT and inversion/eversion 1st MTT (red sensor), tibia rotation (blue sensor) and femur rotation (green sensor).

The four sensors comprising it were previously placed: 1 on the dorsal area of the proximal phalanx of the first toe (yellow sensor), 2 on the medial area of the diaphysis of the first metatarsal (red sensor), 3 on the anterior tibial tuberosity (blue sensor) and 4 on the femur greater trochanter (green sensor), to observe and understand the movement along the three space planes. and the measurement was taken in two ways: 
To perform this measurement, we had to previously configure the Bioval ${ }^{\circledR}$ system such that four sensors were interconnected, interdependent on one another; inter-movements were quantified. Measurement commenced when we raised the first toe, with the toe in relaxed position, continued whilst we placed this under an EVA wedge with a $45^{\circ}$ angle and ended when we removed the wedge (Figure 1). Among all the values obtained with this measurement, we took the maximum value as a reference.

2. Extension 1st MTPJ with independent sensors:

In this case, the Bioval ${ }^{\circledR}$ system must present an independent system, quantifying in an

143 isolated manner the degree of movement for each one of the sensors. In this case, the 1st MTPJ 144 was extended to maximum twice, consecutively, with a time interval of 5 seconds between each 145 one of them. Measurement commenced when we raised the first toe, with the toe in relaxed 146 position and ended when we placed the first toe in a relaxed position (Figure 2). Among all the 147 values obtained with this measurement we took two values as reference. First, the value similar or 148 equal to $45^{\circ}$ extension and second, the maximum value.

All these measurements were performed on the right foot; sensor movement was recorded 150 for 30 seconds.

The variables included in this study were classified as descriptive (sex, age, weight, 152 height, BMI, Helbing line, FPI and STJ localisation axis) dependent (plantarflexion and 153 inversion/eversion of the 1st metatarsal, rotation of the tibia and femur) and independent 154 (extension of the 1st MTPJ). 
A descriptive analysis of the variables included in the study was performed based in the

157 distribution of the sample, using the Shapiro-Wilks test. To determine whether statistical 158 significance was attained we will use Student's t-Test or the Wilcoxon rank sum test for two 159 related samples and to evaluate the correlation between variables Pearson test or Spearman's Rho 160 test will use. Data analysis was performed using the programme Statistical Package for the Social 161 Sciences version 22.0 (SPSS Inc, Chicago, Illinois, USA). A significance level of 0.05 was used 162 for all statistical procedure.

\section{RESULTS}

164 The study population was comprised of 15 subjects $(\mathrm{N}=15), 11$ women and 4 men aged 165 between 20 and 27 years.

166 Results were analysed according to the set order in the data collection.

We analysed the distribution of dependent and independent variables for each study

168 situation by means of the Shapiro-Wilks Test (Table 1); a non-normal distribution predominated.

Because this is a non-normal distribution, the median and interquartile range were analysed for each variable, in addition to maximum and minimum value to measure the amount 171 of data variation or dispersion (Table 2-4). values with $45^{\circ}$ extension and maximum values of the joint for each variable with independent 174 sensors, we used the Wilcoxon rank sum test, where we found statistically significant differences

175 for extension of the 1st MTPJ, inversion/eversion and plantar flexion of the 1st metatarsal (Table 176 5). 

were related, the results revealed a direct correlation among the variables extension-plantar flexion of the 1st MTPJ and rotation of the femur, and inverse correlation between the latter and the variable inversion/eversion of the 1st metatarsal (Table 6).

In the situation which the sensors were independent and in $45^{\circ}$ extension, no correlation whatsoever was found between the variables.

Finally, the results obtained in the sensors with independent configuration and maximal extension of the 1st MTPJ, revealed a direct relationship between the variables extension of the 1st MTPJ and plantar flexion of the 1st metatarsal, in addition to extension of the 1st MTPJ and inversion/eversion of the 1st metatarsal. Correlation was also obtained between the variables plantar flexion and inversion/eversion of the 1st metatarsal, inversion/eversion of the 1 st metatarsal and rotation of the femur and among the variables tibia and femur rotation (Table 6).

\section{DISCUSSION}

This study aims to quantitatively determine in subjects that comply with set inclusion and exclusion criteria, angular changes that occur in the leg during onset and development of the WM passively, with a determined extension of the 1st MTPJ using an inertial sensor system. quantified, using kinematic analysis, movements produced after activation of the WM. These movements allude to the entire leg, not only the tibia ${ }^{1,8,9,11,25,26}$, but also the femur. with the sensors configured in a dependent manner, median extension of this joint was $8.83^{\circ} \pm$ 
200 undermined by not considering the soft tissues that make up this joint. Continuing this 201 measurement, the median obtained for the remaining variables are not very significant and almost 202 negligible, leading to $2.80^{\circ} \pm 9.80$ in inversion-eversion, $0.27^{\circ} \pm 0.87$ in the tibia and $0.42^{\circ} \pm 0.71$

203 in the femur. As we observed, there were less changes the further we moved from the WM main 204 joint.

If we compare our results in maximum extension with the literature consulted, we verify 206 that our value is $47.59^{\circ}$. Authors such as Nester ${ }^{27}$, Halstead ${ }^{28}$ and Nawoczenski ${ }^{29}$ consider this value within the normal range of motion of the $1^{\text {st }}$ MPTJ. However, Root ${ }^{9}$ considers that at least $60^{\circ}$ extension is necessary to attain correct plantarflexion of the 1 st metatarsal ${ }^{9}$. In addition to $10^{\circ}$ 209 plantar flexion, according to Root $^{9,30}$, and $22^{\circ}$, according to Fuller ${ }^{8}$ to enable full extension of the 210 toe during the propulsive phase of gait, a value not attained in our measurement, which was $4.12^{\circ}$. situation. The measurement we took is indirect, in which there is an impact of the skin's own movements on the bone structure. These movements were not recorded by the system, leading to loss of information. This observation can be confirmed if we continue to compare values obtained by the three measurements in the remaining variables, where little change was observed among them, despite the different degree of extension.

218 the higher the values obtained in the remaining variables. This confirms the relationship between the WM and rotational movements in the lower extremity. This relationship has less impact as we move up the lower limb. 
223 MLA lifted immediately after joint extension, whilst in others, elevation was significantly

224 delayed. This coincides with these subjects presenting more eversion of the calcaneus during 225 gait $^{26}$.

226 For its part, unlike that suggested by Kappel-Bargas ${ }^{26}$, Aquino's ${ }^{10}$ study, with a sample of 22739 subjects with excessive hindfoot pronation, aimed to analyse the effect of excessive pronation 228 on the WM during gait and list a series of static clinical measurements with the WM in dynamic 229 state. This study reported that $15.4 \%$ of feet were classified as excessively pronated and that there 230 was no statistically significant difference between excessive pronation and visual establishment 231 of the WM. Despite this, Aquino ${ }^{10}$ considered, just like Kappel-Bargas ${ }^{26}$, that the location of the 232 STJ axis, together with other measurements, has an impact on the implementation of an effective 233 WM. This data was also referred to in the study by Cintado ${ }^{31}$, which evaluated the WM as an 234 aspect that stabilised the forefoot and confirms our theory over the importance of a normalised $235 \mathrm{STJ}_{\text {axis }}{ }^{17}$ for it to function correctly. Hence this has formed part of the inclusion criteria in our 236 research work. contraction of the Achilles tendon was evaluated. The results of this study suggested that

240 increased tension in the PF is directly proportional to the increased degree of tension. The 241 strength of the Achilles tendon also increased, which confirmed the results obtained by Carlson ${ }^{33}$ 242 who evaluated how the extension angle of the 1st MTPJ affected the Achilles tendon - PF 243 relationship. Cheng ${ }^{32}$ also demonstrated that the maximum tension during PF stretching is 244 concentrated around the medial tubercle of the calcaneus, and under the head of the first 245 metatarsal $^{32}$. 
247 obtained by Caravaggi ${ }^{34}$ that reproduced the WM by means of a 3D model using the combination 248 of ultrasound and biometry during the gait support phase, are added. A linear relationship was 249 obtained between the maximum tension able to be tolerated by the PF and extension of the $1 \mathrm{st}$ 250 MTPJ.

The results provided by Cheng ${ }^{32}$ and Caravaggi ${ }^{34}$ were very relevant, because the high tension located under the head of the first metatarsal may be associated with compression of the soft tissues present in the area, mainly the gleno-sesamoid system, a possible causal factor among others, of abnormality in our results in regard to extension of the 1st MTPJ.

The most important limitations found in this study refer to sample size and use of the inertial sensor system. Because they are not stuck to the skin, possible movements that occur between the bone segment and the skin are not quantified. This impact has an impact on the movements recorded and some of the information is lost.

As a new research line, we plan to increase sample size; in addition to trying to find a kinematic system able to quantify both degrees of extension of the 1st MTPJ, and rotational movements of the legs, where there is a minimal impact of soft tissues present in the area.

We could also establish a comparison among subjects that meet the normality criteria set and subjects with a tendency towards pronation, thereby enabling us to determine whether or not WM is efficient and its relationship with the foot's functionality.

\section{CONCLUSIONS}

Kinematic analysis of the lower limb movements because of the WM activation suggest 267 that, the more the extension, the more movement will be generated, thereby reducing the level of 268 impact the more distal the structure with respect to the joint. We also state that the soft parts, 
269 mainly the gleno-sesamoid system have an impact on determination of articular movement. The

270 fact of making an extension movement on the phalanx is not indicative of acting on the joint 271 itself. An indirect measurement is therefore taken.

272 We can state that extension of the 1st MTPJ has an impact all over the legs, not only 273 generating an external rotation movement of the tibia. However, because the kinematic system

274 used was not suitable, its impact was not exactly quantified. A system that considers all factors 275 that interfere with recording movement, such as the soft tissues, needs to be found or created.

\section{REFERENCES}

277 1. Hicks JH. The mechanics of the foot. II: The plantar aponeurosis and the arch. J Anat. 1954; $278 \quad 88: 25-30$

279 2. Durrant B. Functional Hallux Limitus; A Review. JAPMA. 2009; 99: 236-243.

280 3. Harradine P, Bevan L, Carter N. An overview of podiatric biomechanics theory and its 281 relation to selected gait dysfunction. Physiotherapy. 2006; 92: 122-1277.

282 4. Harton FM, Weiskopf SA, Goecker RM. Sectoring the Plantar Fascia, Effect on First 283 Metatarsophalangeal Joint Motion. JAPMA. 2002; 92: 532-536.

284 5. Kirby KA. Foot and Lower Extremity Biomechanism: A Ten Year Collection of Precision 285 Intricast Newsletter. Payson, Arizona: Precision Intricast; 1997.

286 6. López A. 2012. Propuesta de valoración del daño corporal en la primera articulación 287 metatarsofalángica según funcionalidad y repercusión en la marcha. Thesis, Universidad de Murcia. 
289

290

291

292

293

294

295

296

297

7. Paton JS. The Relationship Between Navicular Drop and First Metatarsophalangeal Joint Motion. JAPMA. 2006; 96: 313-317.

8. Fuller EA. The Windlass Mechanism of the Foot A Mechanical Model to Explain Pathology. JAPMA. 2000;90(1):35-46.

9. Munuera PV. El primer radio. Biomecánica y Ortopodología. 2nd ed. Cádiz: Exa Editores SL; 2009: 3-54.

10. Aquino A, Payne C. Function of the Windlass mechanism in excessively pronated feet. JAPMA. 2001;91(5):245-250.

11. Bolgla LA, Malone TR. Plantar Fasciitis and the Windlass Mechanism: A Biomechanical Link to Clinical Practice. J Athl Train. 2004;39(1):77-82.

12. Song S, Lamontagna C, Collins SH, Geyer H. The Effect of Foot Compliance Encoded in the Windlass Mechanism on the Energetics of Human Walking. 35TH Annual International Conference of the IEEE EMBS. Osaka, Japan; 2013: 3179-3182.

13. Shapiro F, Forriol F. Growth cartilage: Developmental biology and biomechanics. El cartílago de crecimiento: Biología y biomecánica del desarrollo. Rev Ortop y Traumatol. $2005 ; 49(1): 55-67$.

14. Sell KE, Verity TM, Worrell TW, Pease BJ, Wigglesworth J. Two measurement techniques for assessing subtalar joint position:a reliability study. J Orthop Sports Phys Ther. 1994; 19 (3): 162-167.

15. Pascual R, Redmond AC, Alcacer B, López P. García J, López P. Índice de Postura del Pie (IPP-6) versión de seis criterios, Manual y guía del usuario. Podol Clínica. 2013; 14(2): 3645.

16. Redmond A, Crosbie J, Ouvrier R. Development and validation of a novel rating system for scoring standing foot posture: The Foot Posture Index. Clin Biomech. 2006;21(1):89-98. 
313 17. Kirby K. Subtalar joint axis location and rotational equilibrium theory of foot function. $314 \quad$ JAPMA. 2001;91(9):465-487.

315 18. AMM (Asociación Médica Mundial). Declaración de Helsinki. Principios éticos para las 316 investigaciones médicas en seres humanos. $18^{a}$ Asamblea Médica Mundial. Helsinki 317 (Finlandia). 1964. Available at: http://www.wma.net/es/30publications/10policies/b3/. $318 \quad$ Accessed October 15, 2015.

319 19. Consejo de Europa. Convenio para la protección de los Derechos Humanos y la dignidad 320 del ser humano con respecto a las aplicaciones de la Biología y la Medicina. Convenio sobre los Derechos Humanos y la Biomedicina. Oviedo. 1997. Available at: http://www.unav.es/cdb/coeconvencion.html. Accessed October 15, 2015.

20. Munuera PV. 2006. Factores morfologicos en la etiología del hallux limitus yel hallux abductus. Thesis. Universidad de Sevilla.

21. Munuera PV, Dominguez G, Polo J, Rebollo J. Medial desviation of first metatarsal incipient 326 hallux valgus deformity. Foot Ankle Int. 2006; 27 (12): 1030-5.

22. Ramos J, Domínguez G, Castillo JM, Fernández L, Munuera PV. Angular position of the cleat according to torsional parameters of the cyclist's lower limb. Clin J Sport Med. 2014;

23. Grand JM, Geronimi M. Scapulohumeral rhythm assessment with inertial sensors: preliminary results. Comput Methods Biomech Biomed Engin. 2011;14(sup1):61-63. Biomecánica y Podología Deportiva. Barcelona 21 y 22 de Junio, 2013. 
334 25. Chana P. 2013. Eficacia de los impulsos eléctricos de bajo voltaje en la fasciosis plantar.

335 Thesis, Universidad Complutense de Madrid.

336 26. Kappel-Bargas A, Mcpoil TG, Woolf RD, Cornwall MW. The Windlass mechanism during 337 normal walking and passive first metatarsalphalangeal joint extension. Clin Biomech. $338 \quad 1998 ; 13(3): 190-4$.

27. Nester CJ, Jarvis HL, Jones RK, Bowden PD, Liu A. Movement of the human foot in 100 pain free individuals aged 18-45: implications for understanding normal foot function. $J$ Foot Ankle Res. 2014; 7: 51.

28. Halstead J, Redmond AC. Weight-bearing passive dorsiflexion of the hallux in standing is not related to hallux dorsiflexion during walking. J Orthop Sports Phys Ther. 2006;

29. Nawoczenski DA, Baumhauer JF, Umberger BR. Relationship between clinical 36(8):550-6.

30. Root M, Orien W, Weed J. Normal and abnormal function of the foot. Vol 2. Los Angeles: Clinical Biomechanics Corp; 1977.

31. Cintado R, Domínguez G, López del Amo A, Benhamú S, Jiménez M. Mecanismo de Windlass y su importancia en el movimiento del primer dedo. Podol Clínica. 2013;14(3):7077.

32. Cheng HK, Lin C, Wang H, Chou S. Finite element analysis of plantar fascia under stretch. The relative contribution of windlass mechanism and Achilles tendon force. $J$ Biomech. $2008 ; 41: 1937-1944$. 
356 33. Carlson RE, Fleming LL, Hutton WC. The biomechanical relationship between the 357 tendoachilles, plantar fascia and metatarsophalangeal joint dorsiflexion angle. Foot Ankle $358 \quad$ Int. 2000; 21(1):18-25.

359 34. Caravaggi P, Pataky T, Goulermas JY, Savage R, Crompton R. A dynamic model of the 360 Windlass mechanism of the foot: evidence for early stance phase preloading of the plantar $361 \quad$ aponeurosis. J Exp Biol. 2009; 212 (Pt 15):2491-2. 
Figure 1

Extension 1st MTPJ with the $45^{\circ}$ angle wedge.

Photo credit: María José Manfredi Márquez.

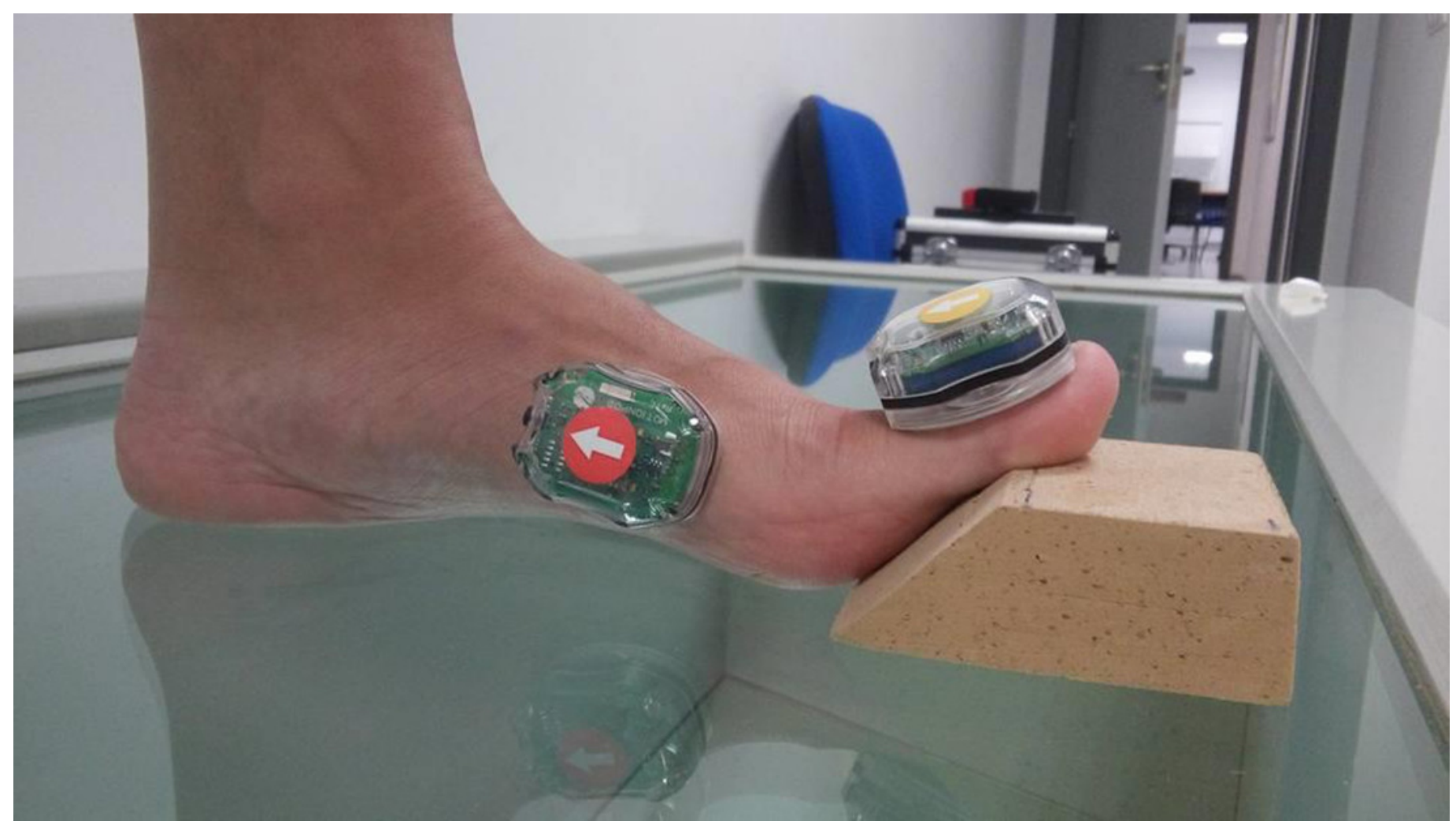




\section{Figure 2}

\section{Extension 1st MTPJ.}

Photo credit: María José Manfredi Márquez.

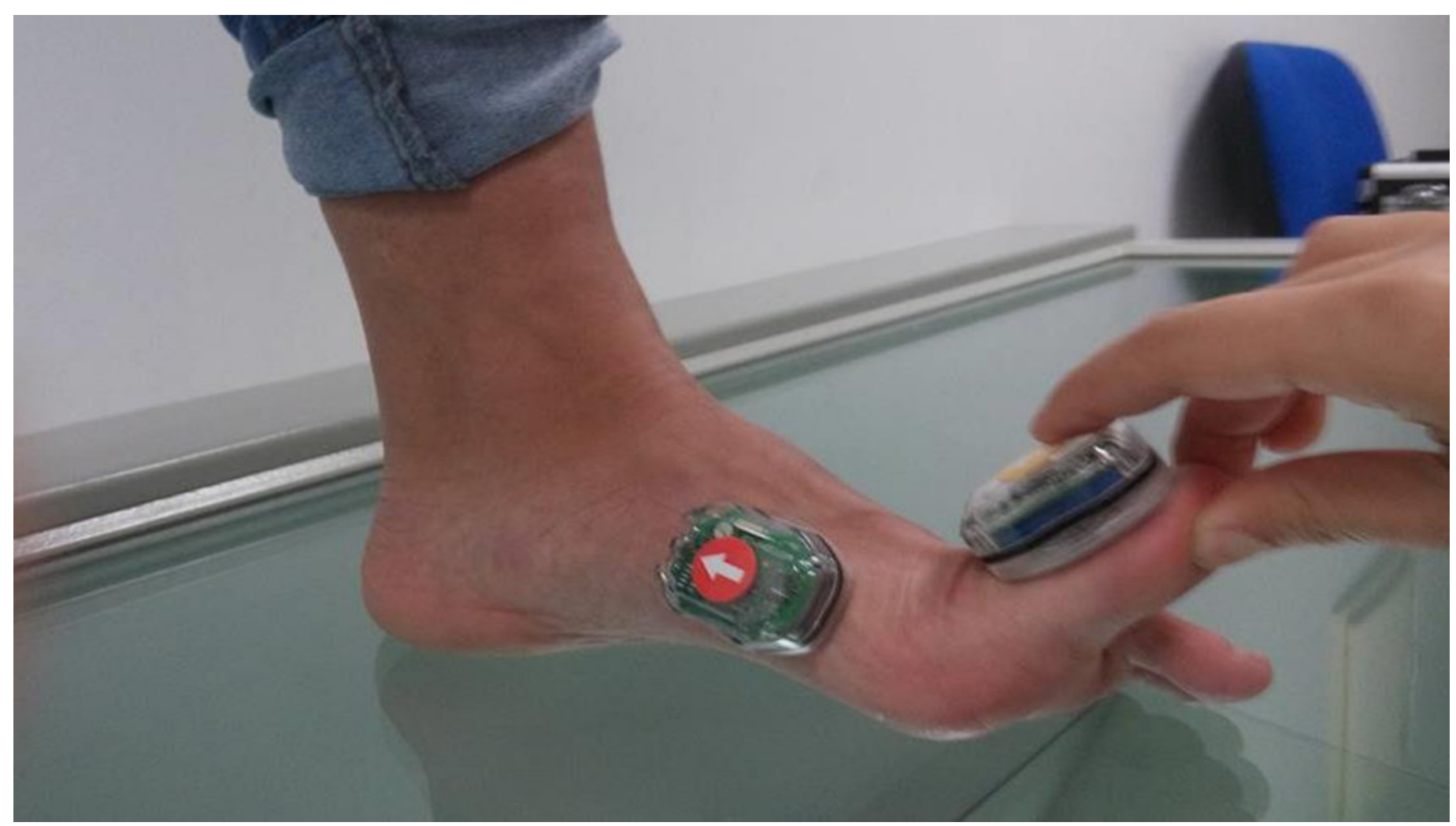




\section{Table $\mathbf{1}$ (on next page)}

Normality tests.

Shapiro-Wilk - Extension 1st MTPJ with EVA-wedge 45o - dependent sensors. Extension 1st MPTJ - independent sensors. 
Normality tests: Shapiro-Wilks Test-Extension 1st MTPJ with EVA-wedge $45^{\circ}$ - dependent sensors. Extension 1st MPTJ-independent sensors.

3

4

5

7

8

9

10

11

12

13

\begin{tabular}{cccc}
\hline Extension 1st MTPJ & $<\mathbf{0 . 0 1}$ & $<\mathbf{0 . 0 1}$ & 0.96 \\
\hline Plantar flexion 1st MTT & - & 0.18 & 0.75 \\
\hline $\begin{array}{c}\text { Inversion-Eversion 1st } \\
\text { MTT }\end{array}$ & $<\mathbf{0 . 0 1}$ & $<\mathbf{0 . 0 1}$ & $<\mathbf{0 . 0 1}$ \\
\hline Tibia Rotation & $\mathbf{0 . 0 4}$ & $\mathbf{0 . 0 1}$ & 0.09 \\
\hline Femur Rotation & $<\mathbf{0 . 0 1}$ & $<\mathbf{0 . 0 1}$ & $<\mathbf{0 . 0 1}$ \\
\hline Location STJ axis & $\mathbf{0 . 0 1}$ & $\mathbf{0 . 0 1}$ & $\mathbf{0 . 0 1}$
\end{tabular}


Table 2 (on next page)

Descriptive statistic results.

Extension 1st MPTJ with EVA-wedge 45ㅇ - dependent sensors. 
Descriptive Statistic Results - Extension 1st MPTJ with EVA-wedge $45^{\circ}$ - dependent sensors.

2

3

4

5

6

7

8

9

10

11

12

13

\begin{tabular}{cccccc}
\hline & $\begin{array}{c}\text { Extension } \\
\text { PF 1st } \\
\text { MPTJ }\end{array}$ & $\begin{array}{c}\text { Inversion- } \\
\text { Eversion 1st } \\
\text { MTT }\end{array}$ & $\begin{array}{c}\text { Tibia } \\
\text { Rotation }\end{array}$ & $\begin{array}{c}\text { Femur } \\
\text { Rotation }\end{array}$ & STJ \\
\hline Median & 8.83 & 2.80 & 0.27 & 0.42 & 8 \\
\hline Minimal & 5.24 & 0.18 & 0.01 & 0.03 & 7 \\
\hline Maximum & 37.64 & 35.71 & 1.77 & 3.72 & 14 \\
\hline $\begin{array}{c}\text { Interquartile } \\
\text { Range }\end{array}$ & 14.13 & 9.80 & 0.87 & 0.71 & 3 \\
\hline
\end{tabular}

$* 1^{\text {st }}$ MPTJ: First metatarsalphalangeal joint

EVA: Ethylene Vinyl Acetate

$1^{\text {st }}$ MTT: First metatarsal

STJ: Subtalar Joint

PF: Plantar-flexion 
Table 3 (on next page)

Descriptive statistics results.

Extension $45 \cong 1$ st MTPJ. Independent sensors. 
1

2

3

4

5

6

7

8

9

10

11

12

13

14

13

Descriptive Statistics Results - Extension $45^{\circ} 1$ st MTPJ. Independent Sensors.

2

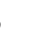

\begin{tabular}{lcccccc}
\hline Extension & PF & Inversion- & Tibia & Femur & STJ \\
1st MPTJ & $\begin{array}{c}\text { 1st } \\
\text { MTT }\end{array}$ & $\begin{array}{c}\text { Eversion } \\
\text { 1st MTT }\end{array}$ & Rotation & Rotation & \\
& & &
\end{tabular}

\begin{tabular}{ccccccc}
\hline Median & 44.99 & 3.67 & 2.06 & 0.3 & 0.52 & 8 \\
\hline Minimal & 34.31 & 1.03 & 0.01 & 0.06 & 0.02 & 7 \\
\hline Maximum & 45.21 & 6.63 & 28.64 & 1.69 & 4.70 & 14 \\
\hline $\begin{array}{c}\text { Interquartile } \\
\text { Range }\end{array}$ & 3.37 & 1.95 & 2.96 & 0.77 & 1.85 & 3 \\
\hline
\end{tabular}

$*^{\text {st }}$ MPTJ: First metatarsalphalangeal joint

$1^{\text {st }}$ MTT: First metatarsal

STJ: Subtalar Joint

PF: Plantar-flexion 


\section{Table 4(on next page)}

Descriptive statistic results.

Maximum extension of the 1st MPTJ. Independent sensors. 
1 Descriptive Statistic Results - Maximum Extension of the 1st MPTJ. Independent Sensors.

2

3

4

5

6

7

\begin{tabular}{lllcccc}
\hline Extension & PF & Inversion- & Tibia & Femur & STJ \\
1st MPTJ & 1st & eversion & Rotation & Rotation & \\
& MTT & 1st MTT & & &
\end{tabular}

\begin{tabular}{ccccccc}
\hline Median & 47.59 & 4.12 & 2.08 & 0.49 & 1.04 & 8 \\
\hline Minimal & 34.31 & 1.03 & 0.51 & 0.02 & 0.17 & 7 \\
\hline Maximum & 63.03 & 7.78 & 28.64 & 1.69 & 4.7 & 14 \\
\hline $\begin{array}{c}\text { Interquartile } \\
\text { Range }\end{array}$ & 11.55 & 3.06 & 3.07 & 0.67 & 0.87 & 3 \\
& & & & & & \\
\hline
\end{tabular}

8

* $1^{\text {st }}$ MPTJ: First metatarsalphalangeal joint

$1^{\text {st }}$ MTT: First metatarsal

12

STJ: Subtalar Joint

13 


\section{Table 5(on next page)}

Wilcoxon Rank Sum Test

Extension 45--Maximal for the 1st MPTJ. Independent sensors. 
1 Wilcoxon Rank Sum Test-Extension 45-Maximal for the 1st MPTJ. Independent Sensors.

2

\begin{tabular}{cccccc}
\hline & $\begin{array}{c}\text { Inversion- } \\
\text { Extension_max - } \\
\text { Extension_IAMTF }\end{array}$ & $\begin{array}{c}\text { PF1_max - } \\
\text { PF1 }\end{array}$ & $\begin{array}{c}\text { eversion_max }- \\
\text { Inversion- } \\
\text { eversion_1mtt }\end{array}$ & $\begin{array}{c}\text { Rot_tib_max - } \\
\text { Rot_Tib }\end{array}$ & $\begin{array}{c}\text { Rot_femur_max } \\
\text { - Rot_Femur }\end{array}$ \\
\hline $\mathbf{Z}$ & $-2,803$ & $-2,803$ & $-2,528$ & $-1,079$ & $-1,428$ \\
\hline $\begin{array}{c}\text { Sig. asintót. } \\
\text { (bilateral) }\end{array}$ & 0,005 & 0,005 & 0,011 & 0,281 & 0,153 \\
& & & & & \\
\hline
\end{tabular}

3

4 


\section{Table 6 (on next page)}

Correlation test: Spearman's Rho

Extension 1st MTPJ with EVA-wedge 45으 - dependent sensors Maximal Extension 1st MTPJ. 
1 Correlation test: Spearman's Rho - Extension 1st MTPJ with EVA-wedge $45^{\circ}$ - dependent 2 sensors Maximal Extension 1st MTPJ.

Extension 1st MTPJ with $45^{\circ}$ wedge dependent sensors
Maximum Extension 1st MTPJ - independent sensors.

\begin{tabular}{|c|c|c|c|c|c|c|c|c|c|}
\hline & $\begin{array}{c}\text { Extension } \\
\text { - PF } \\
\text { MTPJ }\end{array}$ & $\begin{array}{c}\text { Inversion- } \\
\text { Eversion } \\
\text { 1st MTT }\end{array}$ & $\begin{array}{c}\text { Tibia } \\
\text { Rotation }\end{array}$ & $\begin{array}{c}\text { Femur } \\
\text { Rotation }\end{array}$ & $\begin{array}{c}\text { Extension } \\
\text { 1st MPTJ }\end{array}$ & $\begin{array}{c}\text { PF1st } \\
\text { MTT }\end{array}$ & $\begin{array}{c}\text { Inversion- } \\
\text { Eversion } \\
\text { 1st MTT }\end{array}$ & $\begin{array}{c}\text { Tibia } \\
\text { Rotation }\end{array}$ & $\begin{array}{c}\text { Femur } \\
\text { Rotation }\end{array}$ \\
\hline $\begin{array}{c}\text { Extension } \\
\text { 1st MTPJ }\end{array}$ & 1 & 0.04 & -0.14 & $\mathbf{0 . 5 7}$ & 1 & $\mathbf{0 . 6 6}$ & $\mathbf{0 . 4 3}$ & 0.20 & 0.16 \\
\hline $\begin{array}{c}\text { PF 1st } \\
\text { MTT }\end{array}$ & - & - & - & - & 0.66 & 1 & 0.63 & 0.01 & 0.26 \\
\hline $\begin{array}{c}\text { Inversion- } \\
\text { Eversion } \\
\text { 1st MTT }\end{array}$ & 0.04 & 1 & -0.24 & $\mathbf{- 0 . 3 5}$ & 0.43 & $\mathbf{0 . 6 3}$ & 1 & 0.19 & $\mathbf{0 . 3 9}$ \\
\hline $\begin{array}{c}\text { Tibia } \\
\text { Rotation }\end{array}$ & -0.14 & -0.24 & 1 & 0.07 & 0.20 & 0.01 & 0.19 & 1 & 0.45 \\
\hline $\begin{array}{c}\text { Femur } \\
\text { Rotation }\end{array}$ & $\mathbf{0 . 5 7}$ & -0.35 & 0.07 & 1 & 0.16 & 0.26 & 0.39 & $\mathbf{0 . 4 5}$ & 1 \\
\hline
\end{tabular}

3

4

5

* ${ }^{\text {st }}$ MPTJ: First metatarsalphalangeal joint

6

EVA: Ethylene Vinyl Acetate

7

$1^{\text {st }}$ MTT: First metatarsal

8

STJ: Subtalar Joint

9

PF: Plantar-flexion 